\title{
The dynamics of organisational response: simulating cultural change
}

\section{Colin E. Beech}

CNSI, Computer Systems Functional Lead,

Baton Rouge, Louisiana, 70806, USA

E-mail: colin@colinbeech.org

\author{
Rachel A. Dowty* \\ Department of Geography and Anthropology, \\ Disaster Science and Management Program, \\ Louisiana State University, \\ Baton Rouge, Louisiana, 70803, USA \\ E-mail: rdowty1@1su.edu \\ *Corresponding author
}

\author{
William A. Wallace \\ Department of Industrial and Systems Engineering, \\ Rensselaer Polytechnic Institute, \\ Troy, New York, 12180, USA \\ E-mail: wallaw@rpi.edu
}

\begin{abstract}
The goal of this research is to develop a computer simulation that determines the point at which an organisation's culture will change when responding to disaster situations. Different organisations' cultural biases shape how they resolve accumulated response tasks and deal with the disruptions of novel tasks. Called Organizational Response Culture in Disaster Simulation (ORCiDS), the simulation is applied to four organisations, each with a different cultural bias at the outset of the disaster, to Hurricane Katrina in Louisiana. The data demonstrates how cultural biases lead to different outcomes for organisations that face similar circumstances but have very different cultural lenses for interpreting those circumstances. The importance of this research is to model organisational stability and instability to better enable managers and administrators to circumvent pitfalls associated with poor organisational response. The ultimate goal of this ongoing research is to be able predict the point at which an organisation's culture will change in times of crisis.
\end{abstract}

Keywords: organisational culture; computer simulation; disaster response; cultural theory; Mary Douglas.

Reference to this paper should be made as follows: Beech, C.E., Dowty, R.A. and Wallace, W.A. (2012) 'The dynamics of organisational response: simulating cultural change', Int. J. Complexity in Leadership and Management, Vol. 2, Nos. 1/2, pp.74-103. 
Biographical notes: Colin E. Beech builds computer systems for purposes of social welfare and justice. He served as the Programme Director for the Computers For Kids Program, teaching inner city children to build both computer software and hardware, designed computer simulations for social interaction, and now specialises in state Medicaid computer system design and implementation.

Rachel A. Dowty is an Assistant Professor-Research in the Department of Geography and Anthropology and the Co-Director of the Disaster Science and Management Programme at Louisiana State University. Her research focuses on applications of cultural theory to crises. She received the 2009 ServiceLearning Scholars Award at Louisiana State University for overseeing student designs of disaster plans for local area non-profit organisations. She recently published an edited volume Dynamics of Disaster: Lessons on Risk, Response, and Recovery with Barbara L. Allen (Earthscan, 2011).

William (Al) A. Wallace is a Yamada Corporation Professor in the Industrial and Systems Engineering Department, Rensselaer Polytechnic Institute. He was a member of the National Research Council's Board on Infrastructure and the Built Environment and served on the National Research Council Committee on Social Science Research on Disasters. He received the International Emergency Management and Engineering Conference Award for Outstanding Long-Term Dedication to the Field of Emergency Management, The Institute of Electrical and Electronics Engineers (IEEE) Third Millennium Medal and is a Fellow of the IEEE, and received the 2004 INFORMS President's Award for work that advances the welfare of society.

This paper is a revised and expanded version of a paper entitled 'Modelling organisational culture and disaster response with ORCiDS' presented at the 14th Organization Science Winter Conference (OSWC-XIV), The Resort, Olympic Valley, Squaw Creek, California, USA, 6-10 February 2008.

\section{Introduction}

The goal of this research is to develop a computer simulation that determines the point at which an organisation's culture changes when responding to disaster situations. Our simulation - Organizational Response Culture in Disaster Simulation (ORCiDS) - is based on a model that we developed to identify organisational cultures through statements and actions made by organisational representatives as they grapple to resolve incoming tasks during a crises (Dowty and Wallace, 2010; Dowty et al., 2011). Data was derived from teleconference transcripts, government reports, source-verified newspaper articles, and other texts that directly documented statements made or actions taken by organisational representatives of the United States Coast Guard, the United States Federal Emergency Management Agency (FEMA), the White House, and a group of student volunteers during the response to Hurricane Katrina in New Orleans, Louisiana. We focused on a particular 'mission' undertaken by each of these four organisations during the disaster response:

1 the Coast Guard with its mission of New Orleans search-and-rescue/evacuation

2 FEMA's mission to establish a joint federal-state field office in Baton Rouge

3 the White House and its mission of declaring Katrina a national disaster 
4 an organisation composed of college student volunteers who drove from out of state to New Orleans during Spring Break 2007 in a mission to help aid victims in a community-created volunteer shelter effort.

The understanding of how organisations respond to disasters and crises is largely based on studies of the ways that organisations process disparate information about the situation and act in response to the tasks that are deemed necessary. Researchers have characterised effects of an organisation's task quantity (sheer number of incoming tasks to be resolved) and task novelty (unfamiliarity or rarity of types of tasks to be resolved). Some researchers have designed and implemented computer simulations to model these factors in considering scenarios of how organisations respond to extreme events (e.g., Lin et al., 2006; Lin and Carley, 2003; Rudolph and Repenning, 2002; Carroll and Harrison, 1998,; Prietula et al., 1998; Lin, 2002; Belardo et al., 1983). These studies as a whole provide a fruitful understanding of the organisational processing of tasks. But like any modelling, the results are subject to assumptions about the organisational context and the nature of organisational decision-making.

One of the key contributions of analysing the cultural perspective of organisations is recognition of the fact that organisational contexts and decision-making considerations are greatly influenced by the ways in which those within organisations interpret their world - their shared sense of organisational life and purpose. We consider how organisational culture shapes an organisation's approach to resolving both routine and novel tasks, maintaining group cohesiveness, and use of rules during a disaster response. Our consideration of how organisational culture shapes these factors provides insights into the different responses of organisations to what objectively appear to be similar crisis situations. Our empirical modelling of multiple rational responses (based on culture) during crisis breaks new ground in the study of organisational culture. We achieve this by quantifying the effects of distinct cultural biases on organisational responses to crises.

The study of cultural influences on organisational responses to extreme events (i.e., crises and disasters) presents two research challenges. One challenge is to identify sets of cultural influences that provide meaningful differences in their shaping of organisational responses. The second challenge is to identify the factors that are potentially influenced by cultural differences. Categories used to classify organisational cultures or types are quite varied and include demographic categories (Chatman et al., 1998), cultural 'styles' (Klein et al., 1995), shared beliefs, shared values, and influence (Smircich, 1983; Ouchi and Wilkins, 1985; Marcoulides and Heck, 1993; Chatman and Jehn, 1994; Harrison and Carroll, 2002), and different categories of high-reliability organisations (e.g., Schulman, 1993). Some approaches to organisational culture include roles of 'collectivism' or 'altruism' as attitudes that shape other aspects of organisational culture but are neglected through excessive focus on hierarchy and individualism. Yet, most proposed classification typologies for organisational cultures develop these 'collectivist' cultural forces as little more than influential attitudes (Thompson et al., 1990; Tierney et al., 2001).

Notwithstanding, the contributions of the various scholars who have wrestled with different aspects of organisational culture, we find that Mary Douglas' typology of cultural biases is particularly fruitful for the study of organisational responses to extreme events (also see Rayner, 1992; Thompson et al., 1990; Hood 1998; Coyle, 1997). According to Douglas (1982), a 'cultural bias' can be characterised with respect to two dimensions: the rigidity of its internal and external use of rule structures in interactions 
('GRID' dimension) and its social cohesiveness and relation to outsiders ('GROUP' dimension). The four possible combinations of these two dimensions lead to identification of four types of cultural bias: individualist, hierarchist, egalitarian, and fatalist.

Several considerations make the GRID-GROUP typology appealing for our purposes. The classification into a four-fold typology makes this perspective more parsimonious than more elaborate classification schemes. The categories of organisational culture are based on mutually exclusive, jointly exhaustive, and consistent criteria. As we discuss, the typology's wide applicability to social groups and institutional forms has attracted numerous specific applications, although very few, with the exception of Hood (1998) have attempted to apply it as we do to the study of organisational responses to extreme events.

The second challenge, identifying relevant factors in organisational crisis responses that are culturally shaped, presents a similarly bewildering array of possibilities. We focus on those factors that prior organisational scholars have identified as particularly relevant for empirical models and simulations of such responses: task quantity overload and task novelty. Task quantity overload is an important contributor to organisational stress during crisis. Rudolph and Repenning (2002) proposed a model of organisational stress to indicate how the sheer quantity of 'interruptions' can create crises through a buildup of routine tasks. The computer simulation they developed with Vensim modelling software illustrated how organisations respond to an overwhelming number of routine (not novel) tasks. We enumerate task quantity on a daily basis, tracking how many tasks are resolved and how many tasks remain unresolved at the end of each day until the overall mission is resolved. For our model, task-quantity resolution occurs not only when the organisation we are studying successfully completes tasks and accomplishes goals but also when it 'passes the buck' to other organisations or persons so that it no longer claims responsibility for the task's resolution.

Task novelty has been a focus of organisational and disaster research literature for many years (Perrow, 1994; Weick, 1993; Vaughan, 1996; Turner, 1978; Shrivastava et al., 1988; Comfort et al., 2004). These studies generally address the ways in which discordant information or novel events impact individual and organisational performance. We frame the notion of task novelty relative to the ways in which organisational representatives enact rule structures and maintain group cohesiveness. By approaching task novelty as something that arises from how rules are applied and how group solidarity is maintained within an organisation, almost anything an organisational representative says or does while acting in the name of the organisation can contribute to knowledge about how that organisation makes sense of discordant information or novel events.

Using data that characterise the response of these organisations, we were able to empirically model differences among organisations in group cohesiveness and in the application of rules to consider the impacts of the quantity of tasks and task novelty during crisis responses. We assumed that task novelty is a function of how effectively an organisation's dominant cultural bias can enable its representatives to reason and resolve tasks given a certain set of contexts and circumstances. As indicators of the organisation's group cohesiveness or solidarity ('GROUP') and applications of rule structures ('GRID') in changing contexts, we used statements and actions made by representatives acting in the name of an organisation while responding to non-routine (novel) or extreme events. 


\section{Overview of applied cultural theory}

Douglas (1999) defined a cultural bias as 'a steady preference for one or another set of institutional forms and the consequent commitment to the kinds of knowledge that go with it'. These preferences for organisational management can be for:

1 rigidly regulated and close-knit groups with tight boundaries to outsiders (hierarchist, HIGH GRID, HIGH GROUP)

2 looser rules and loose group ties (individualist, LOW GRID, LOW GROUP)

3 rigid rules but loose group boundaries (fatalist, HIGH GRID, LOW GROUP)

4 less rigid rules and tightly knit group boundaries (egalitarian, LOW GRID, HIGH GROUP).

All four cultural biases are constantly present and competing. But the way that the organisation structures and conducts daily affairs sets up preferences for a dominant bias that individuals adopt when acting in the name of the organisation. In other words, an organisation exhibits a dominant cultural bias at any one time, but ongoing competition among the possible biases makes organisational culture dynamic. An organisation's cultural bias is only as stable as its underlying cultural rationality. That rationality, in turn, is based on preferred kinds of knowledge management, which are the types of information and ways of collecting it that are used to form conclusions.

The GRID-GROUP typology's wide applicability to social groups and institutional forms has attracted no shortage of specific applications. Researchers of perception (Douglas, 1982), risk (Rippl, 2002; Douglas, 1994; Rayner, 1992; Douglas and Wildavsky, 1983), environmental issues (Ellis and Thompson, 1997; Poortinga et al., 2002; Grendstad and Selle, 1997), management (Hood, 1998), and political cultures (Thompson et al., 1990; Coyle and Ellis, 1994) have all used the GRID-GROUP typology and have offered suggestions for development and improvement. Aside from areas where risk studies meet disaster management studies, specific use of cultural biases to understand organisations responding to disasters has a more limited history (Altman and Baruch, 1998; Maesschalck, 2004; Frosdick, 1995; MKC-EPU, 2004). Hood (1998) characterises the path to organisational failure and collapse, based on each bias' 'inbuilt Achilles' Heel' and how it affects an organisation's preferences and actions when responding to crises. Helping to alleviate this shortage of cultural bias application to organisational crisis response is one of this paper's contributions.

To characterise these processes of reasoning and resolving tasks, we turned to Thompson et al.'s (1990) developments of Douglas' cultural theory. One contribution of their work to the development of Douglas' theory posited that each cultural bias characterises a certain understanding of how Nature will influence any given situation, and thus each cultural bias will perceive the actions of Nature as a whole differently (i.e., each cultural bias holds a different 'myth of nature') and will manage resources accordingly. Thus, a task is more novel to an organisation when actions taken or statements made by representatives reflect a myth of nature that does not correspond to the organisation's dominant cultural bias in a given situation. In such cases, small groups of organisational representatives may adopt a different cultural bias from the one they normally work under (the organisation's dominant cultural bias) to resolve tasks when responding to extreme events. According to Thompson et al.'s developments, people can 
switch from one cultural bias to another to rationalise resource management and the statements and actions of others when expectations are unmet.

Below we explain each cultural bias, its myth of nature as posited by Thompson et al., and a set of what we call 'functional forms' to correspond to each myth of nature and cultural bias. Each of the four functional forms below is a mathematical interpretation we developed for the four cultural biases and their respective myths of nature. They are attempts to quantitatively capture behaviours of task resolution during a disaster response based on the qualitative characterisations presented by Thompson et al. based on Douglas's original identification of four parsimonious cultural biases.

The functional forms are what allowed us to characterise modes of organisational work (i.e., modes of task resolution) for each cultural bias:

1 on a routine basis

2 when responding to task backlogs ('task queues') and novel tasks in a crisis.

We delineate a 'crisis threshold' (CT) beyond which an organisational group's mode of work changes according to the functional form. In the case where task resolution ceases to follow the functional form of one cultural bias and begins to follow that of another cultural bias (based on novelty response), we describe the point of change as a 'quadrant threshold' (QT). This refers to the four quadrants created when the four cultural biases are positioned relative to the two dimensions of GRID (vertical dimension) and GROUP (horizontal dimension). The QT is represented by the lines delineating continua of HIGH GRID to LOW GRID and HIGH GROUP to LOW GROUP, which separates each of the cultural biases (represented by the four quadrants) from each other. See Figure 1 for this graphical depiction.

Figure 1 Cultural biases based on GRID/GROUP dimensions

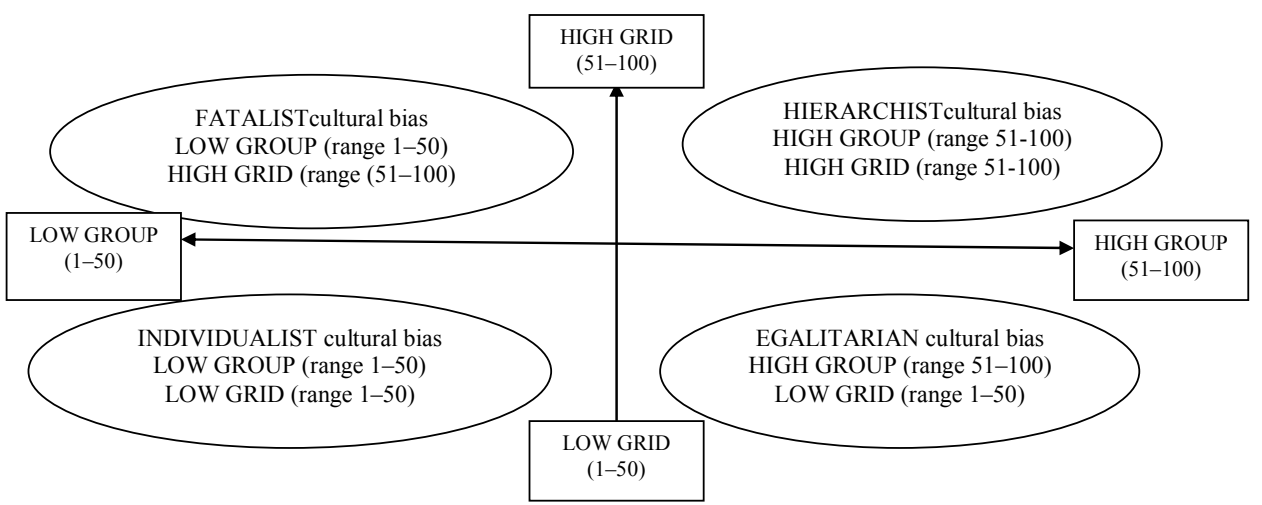

\subsection{Fatalist}

Fatalist organisations view circumstances in the world as inherently random. Managers of Fatalist organisations simply cope with events, good or bad, as they arrive. Since fatalists believe that nature displays very little consistency, in terms of both windfall and disaster, it is useless to anticipate events in terms of regular boundaries. They believe that no particular margin of error produces 'safety', and no guidelines can exist regarding when 
and how crises might occur. Thompson et al. depict the situation diagrammatically as a ball on a flat horizontal line.

The 'ball' represents an organisation as it copes with daily affairs (including crises), while the 'landscape' represents the natural pressures exerted on the ball in a particular location. Here, nature moves the ball freely and randomly across the landscape. Once the ball is located in a particular position, its own inertia will allow it to remain there: no forces from the landscape itself will cause the ball to move to any other position. As a corollary, environmental 'disaster' is no more or less likely to occur on any one part of the landscape. In Figure 2, we show the fatalist myth of nature with its corresponding functional form that we developed to depict how a fatalist organisation resolves incoming crisis tasks.

Figure 2 Fatalist task-resolution functional form

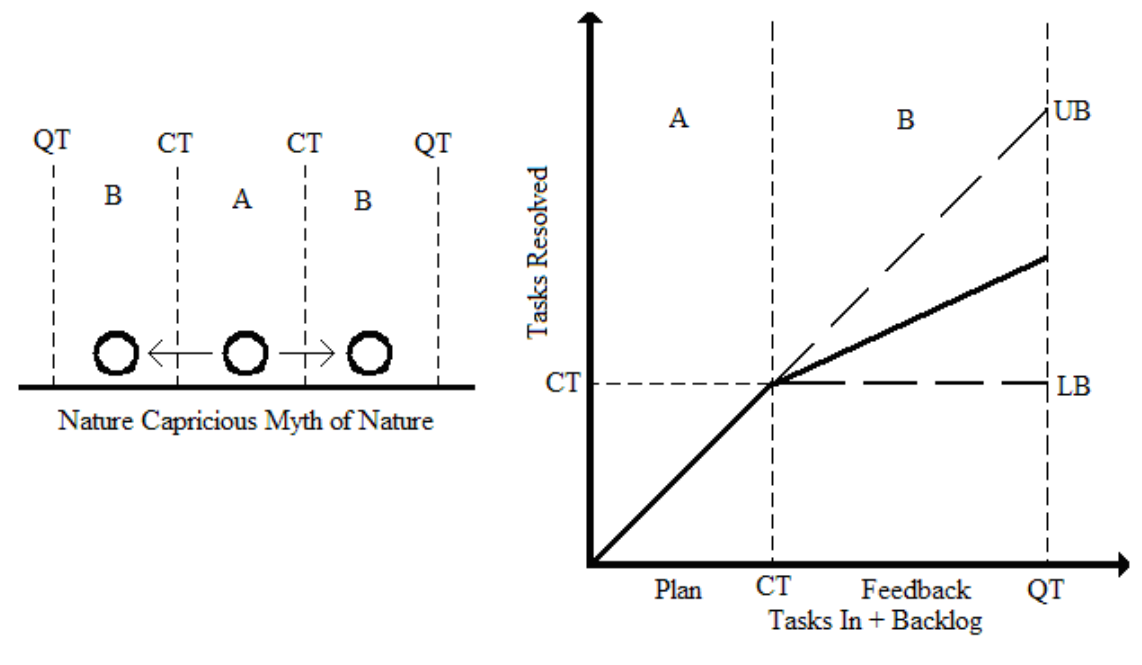

Fatalist Functional Form

The rationale behind the functional form is that any organisation can easily meet the demands placed on it up to a point. This is represented formally as Region A in Figure 2. Within this region, externalities have not shifted the ball on the landscape in a significant way, and tasks can be resolved without the creation of a backlog. In this normative period, the organisation resolves tasks as they are identified.

We defined a 'CT', which is a function of task novelty and available resources to resolve tasks. If an organisation receives a number of tasks greater than its CT (depicted as region B), it is unable to resolve all the tasks identified, and it begins to accrue a task backlog (task 'queue'). During the B period, the parameter $\beta$ controls the slope governing task resolution; $\beta$ is determined by task novelty present in coded statements of a narrative scenario (see Section 3 of this paper). The formal definition of the piecewise continuous functional form is:

$$
\text { For }(0 \leq \mathrm{x} \leq \mathrm{CT}) ; \mathrm{y}=\mathrm{x} \text {. }
$$

For $(\mathrm{CT}<\mathrm{x} \leq \mathrm{QT}) ; \mathrm{y}=\beta \mathrm{x}$, where $(0<\beta \leq 1)$, and for $(\mathrm{Bx}=<\mathrm{CT}), \mathrm{y}=\mathrm{CT}$, where $\mathrm{LB}=\mathrm{CT}$ and $\mathrm{UB}=\mathrm{QT}$ at $\mathrm{x}=\mathrm{QT}$. 
where CT is the crisis threshold and QT is the quadrant threshold.

\subsection{Individualist}

Individualists act in a manner that is consistent with a view of nature as flexible and remarkably resilient. They believe that nature will ultimately reabsorb environmental externalities, and equilibrium will be restored. Crises are thus more matters of inconvenience than disasters. Their myth of nature holds that problems will sort themselves out if the individualists just wait long enough. Thompson et al. (1990) diagram this myth of nature as a ball in the middle of a U-shaped curve (see Figure 3 ).

Figure 3 Individualist task-resolution functional form

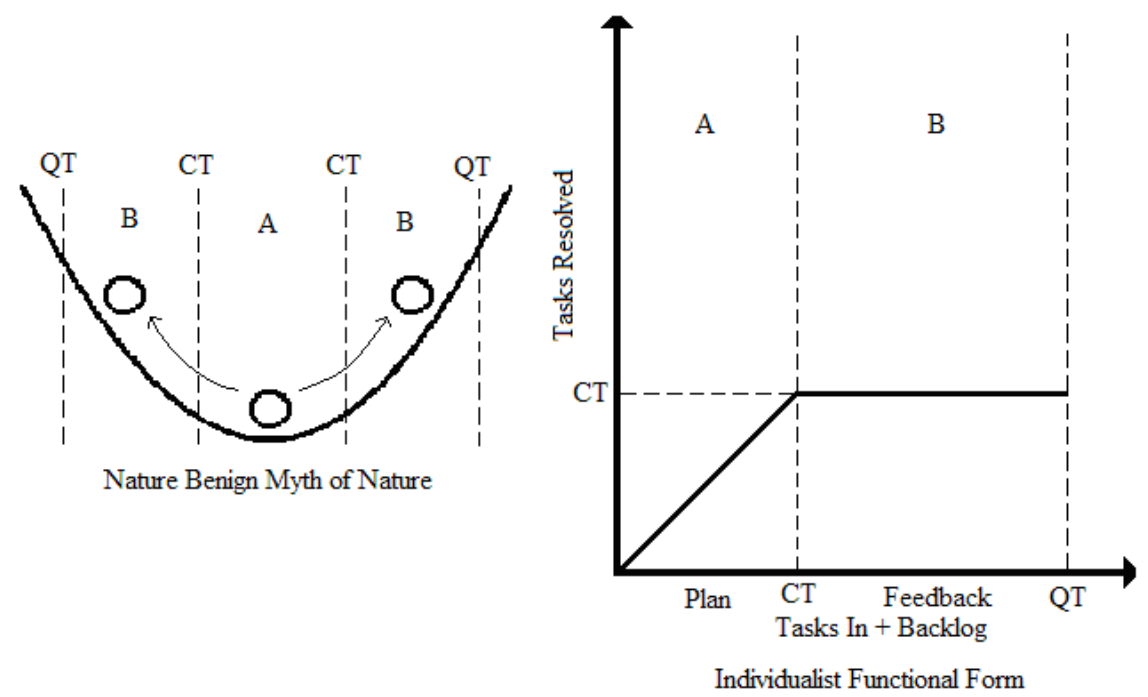

In this case, if the ball (environmental externalities) strays too far out of equilibrium, the landscape itself will eventually push it back into the centre. During crises, agencies in this position will lock on to a certain set of solutions, convinced that they are directly beneficial or, at worst, tangentially helpful. This sort of 'hold the line' behaviour continues until either the tasks resolve themselves, or the infrastructure of the organisation deteriorates to the point where task resolution is no longer possible. It is defined formally as the piecewise continuous functional form:

$$
\text { For }(\mathrm{CT}<\mathrm{x} \leq \mathrm{QT}) ; \mathrm{y}=\mathrm{CT} \text {, where } \mathrm{y}=\mathrm{x} \text { for } 0=<\mathrm{x},=<\mathrm{CT} \text {. }
$$

where CT is the crisis threshold and QT is the quadrant threshold.

\subsection{Egalitarian}

Egalitarians view nature as hanging in a precarious balance, and any externalities threaten to tip that balance into chaos. From this view, disaster is not perceived as something novel to plan for but rather the expected norm as externalities inevitably begin to form a backlog. The distinction between natural disaster and man-made disaster is 
ultimately moot in this view, since natural disasters are found to have some common origin with human action (global warming, for example) or at the very least are clear evidence of the ecosystem's unpredictable churning and upheaval. Thompson et al. (1990) depict this egalitarian myth of nature diagrammatically as a ball on the top of a hill (see Figure 4).

Figure 4 Egalitarian task-resolution functional form

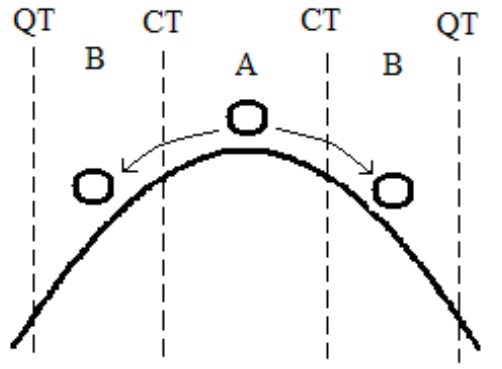

Nature Ephemeral Myth of Nature

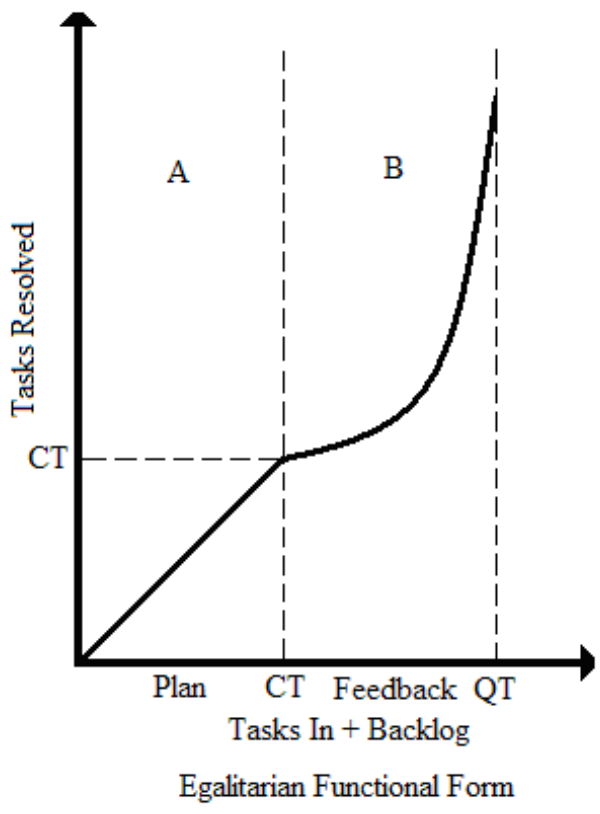

This myth of nature presents a particularly difficult set of challenges to egalitarian managers and policymakers. It begins with the expectation that tasks will arrive rapidly and believes that any backlog must be resolved immediately, lest the situation grow out of control rapidly. Because of this belief, once a crisis begins, the organisation itself takes on an exponential form to address the demands of a precarious nature and resolve tasks in order to offset the exponential increase in incoming tasks. It is defined formally as the piecewise continuous functional form:

$$
\begin{aligned}
& \text { For }(C T<x \leq Q T) \text {; } y=e^{k x}, \text { where }(0<\mathrm{k} \leq 1) \text {, and } \\
& \text { where } y=x \text { for } 0=<x=<C T \text {. }
\end{aligned}
$$

where $\mathrm{CT}$ is the crisis threshold and QT is the quadrant threshold.

\subsection{Hierarchist}

The hierarchist functional form is a hybrid of the individualist and egalitarian myths of nature. The regulated manner and chain of command that is the hallmark of a hierarchist organisation serves the important purpose of establishing where the boundary between equilibrium and chaos resides and then vigorously guarding that threshold. Breaching the boundary will result in the environmental catastrophe that egalitarians believe is always 
impending. Remaining within the boundary, however, will allow the hierarchist organisation to perform within the confines of a committed plan much like the individualist organisation would. Thompson et al. (1990) depict this myth of nature diagrammatically as a ball in a valley between two hills upon which it can roll (see Figure 5).

Figure 5 Hierarchist management task-resolution functional form

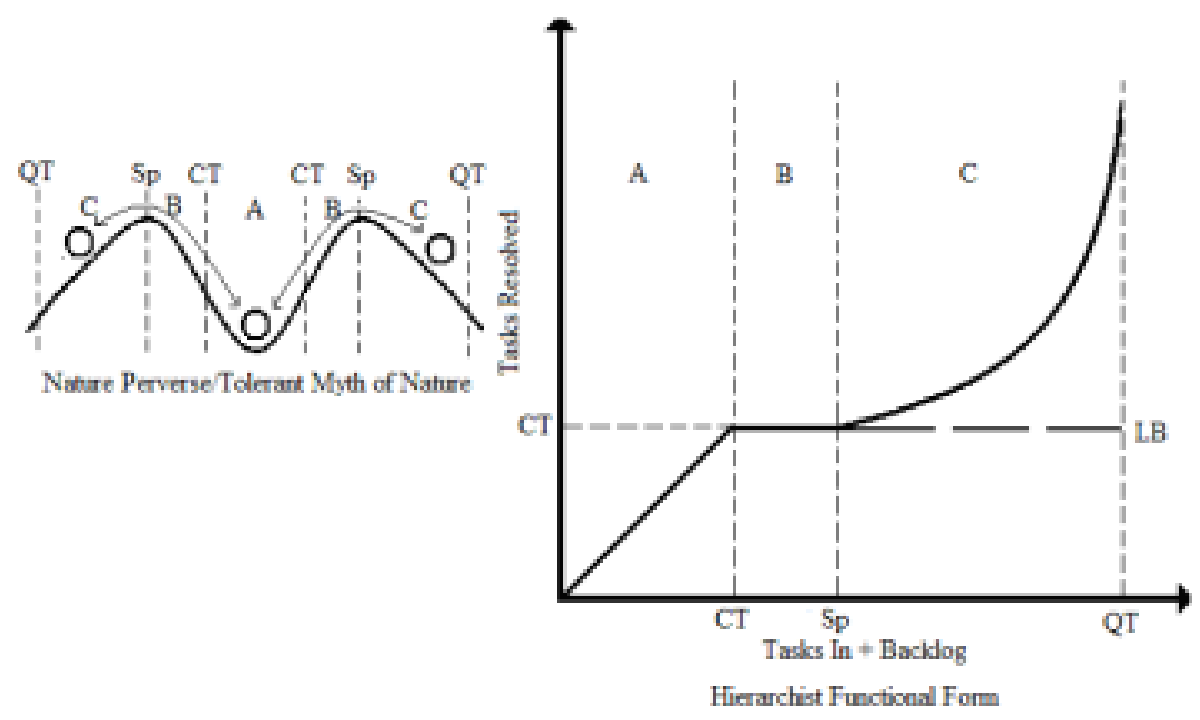

As with its myth of nature, the hierarchist's task-resolution functional form is a hybrid of the individualist and egalitarian functional forms. The functional form is depicted graphically in Figure 5. It is defined formally as the piecewise continuous functional form:

$$
\begin{aligned}
& \text { For }(\mathrm{CT}<\mathrm{x} \leq \mathrm{Sp}) ; \mathrm{y}=\mathrm{CT} \text {, where } \mathrm{y}=\mathrm{x} \text { for } 0=<\mathrm{x}=<\mathrm{CT} \text {. } \\
& \text { For }(\mathrm{Sp}<\mathrm{x} \leq \mathrm{QT}) ; \mathrm{y}=\mathrm{e}^{\mathrm{kx}}, \text { where }(0<\mathrm{k} \leq 1)
\end{aligned}
$$

where CT is the crisis threshold, QT is the quadrant threshold, and Sp is the structural change point (see below).

The governing rationale behind the functional form is a hybrid of the individualist and egalitarian rationales of task resolution. In the hierarchist's myth of nature, Nature can hold her own in terms of remediating externalities (similar to the individualist myth of nature that favours a consistent level of task resolution), but only up to a point. Past that point, however, hierarchist organisations recognise that without immediate intervention, irreparable damage may occur to the affected area during a disaster. During task resolution, we refer to this as the structural change point (Sp), where the hierarchist organisation shifts from an individualist resolution pattern that is best described as 'holding the line', to the egalitarian pattern (after $\mathrm{Sp}$ ) that resolves tasks in an exponential fashion. The $\mathrm{Sp}$ characteristic of hierarchist organisations is due to recognition of the need for immediate action to prevent extraordinary damage. 


\section{Methods}

We developed a protocol to code qualitative data taken from transcripts, source-verified newspaper articles, government reports, and personal accounts such as journals and e-mails that document statements made and actions taken by organisational representatives in response to Hurricane Katrina in Louisiana. We focused on four organisations and identified a mission (composed of tasks) for each:

1 the US Coast Guard with its mission of New Orleans search-and-rescue/evacuation

2 the Federal Emergency Management Agency (FEMA) with its mission to establish a joint federal-state field office in Baton Rouge

3 The White House with its mission of declaring Katrina a national disaster

4 an organisation composed of college student volunteers who drove from out of state to New Orleans during Spring Break 2007 with a mission to help victims in a community-created volunteer shelter effort.

To begin the coding process, we gathered a large collection of government reports, source-verified newspaper articles, transcripts, and other texts that directly documented statements made or actions taken by organisational representatives of the Coast Guard, FEMA, the White House, and the group of student volunteers. Using Thompson et al.'s (1990) detailed descriptions of the characteristics of each cultural bias, we qualitatively assessed each organisation's cultural bias prior to Hurricane Katrina's landfall in Louisiana. We grouped statements made and actions taken by representatives of each of these four organisations, first investigating state and local agencies as well. When we had a final tally of statements and their respective characterisations of a dominant cultural bias, we found that the Coast Guard had the highest/strongest hierarchist cultural bias overall, FEMA had the highest/strongest fatalist cultural bias, the White House had the highest/strongest individualist cultural bias, and the student volunteer group had the highest/strongest egalitarian cultural bias. We tested ORCiDS by using organisations that exhibited a strong affiliation for one of the cultural biases, and represented each cultural bias with one organisation.

During validation of the pre-storm cultural bias for each organisation we studied, we developed four archives of documents, one for each organisation. We selected the documents based on two criteria:

1 they contained verifiable, pertinent information that could be used to determine specific attempts by an organisation to respond to disaster over a given timeline

2 they contained quotes directly attributable to the representatives of the organisation completing a mission.

Referred to as 'statements', these quotes were intended to capture the shifting cultural character of the organisation as it completed its tasks.

Once we had sorted the documents, we read through them and identified potential missions based on the presence of enough logistical information to identify:

1 what tasks were performed

2 by whom they were performed 
3 what timeline of events occurred

4 what statements were made regarding performance during that time period.

Additionally, since the simulation is driven by a discrete time interval, we specified an appropriate time interval in days, although any time interval could be chosen depending on the nature of the archived material (e.g., minutes, hours, days, weeks, months, etc.). We chose the time interval based on the timeline of events described in the archive and the lowest common denominator time interval to which statements reliably referred.

Three graduate research assistant coders then worked to establish a 'case' based on the statements made and actions taken by organisational representatives on consecutive days. To do this, each coder established:

1 the mission

2 the organisation charged with its resolution

3 the organisational representatives or subgroups assigned to complete the mission

4 the tasks undertaken.

The coders then sorted the tasks undertaken according to when organisational representatives began taking actions or making statements aimed at resolving those tasks.

The coders created two lists: a task list and a statement list. The task list was a summary of all tasks present in the archive. Each individual task was followed by an indexing 'tail', comprised of the citation of the article(s) it was culled from, the time interval the task corresponded to, and a qualitative description of the task. For example, a record entry for FEMA might say, 'Move into Joint Field Office (JFO) facility 'Establishing Emergency Management Chain of Command', Paul Smith, July 12, 2007, The New York Times; August 30. Article describes the process of FEMA trying to set up a joint operations facility with local emergency responders)'. The statement list followed the same indexing format but by statement rather than task.

In the next step, researchers coded and sorted the entries in the statement list that were directly attributable to organisational representatives according to:

1 the day on which the statements were made

2 one of six categories in our classification scheme for obtaining HIGH and LOW scores for GRID and GROUP (see Table 1 for a summary of the classification scheme).

Each of the six categories in the scheme was characterised in terms of a continuum from LOW to HIGH and GRID to GROUP. For example, the 'ad hoc vs. explicit procedure' coding table was one of three that pertained to the GRID characteristic of an organisation (the other three pertaining to GROUP). Once a category was selected, coders used qualitative descriptions (based on written guidelines or improvisation) of how a group resolved tasks to determine a score, which was then used to determine the overall GRID characteristic of the group during simulation (along with the other categories and coded statements). 
Table 1 Statement coding schema

\begin{tabular}{lcl}
\hline GRID & Ad hoc to explicit & $\begin{array}{c}\text { The tendency of rules in interaction to be either impromptu } \\
\text { or highly formalised. }\end{array}$ \\
\hline GRID & $\begin{array}{l}\text { Autonomy to } \\
\text { checkpoints } \\
\text { Procurement }\end{array}$ & $\begin{array}{l}\text { The level of bureaucracy individuals must traverse (or its } \\
\text { lack thereof) as they go about daily task resolution. } \\
\text { The manner and ease in which goods are obtained, } \\
\text { including modes of production, markets, and currency. } \\
\text { The organisation's own sense of itself as a successful } \\
\text { organisation, and/or of the solidarity between its members. } \\
\text { WROUP }\end{array}$ Morale \\
GROUP & Blame & $\begin{array}{l}\text { Whengs deviate from plan, the organisation's tendency } \\
\text { to point to external factors or to the poor practices of its } \\
\text { own members. } \\
\text { The organisation's competition over resources and whether } \\
\text { competition tends to be between individual members, with } \\
\text { sub-groups, or with other organisations. }\end{array}$ \\
GROUP & Competition &
\end{tabular}

Once statements were assigned to one of the six categories/continua, the scoring involved assigning each of the statements a HIGH or LOW GRID or GROUP score. LOW GRID and LOW GROUP were represented in intervals of five on a scale from 5 to 50, while HIGH GRID and HIGH GROUP were represented in intervals of five from 55 to 100 . For each numbered interval, we established a qualitative description of the respective characteristics that would justify scoring a statement under a particular category and at a particular interval of five along the GRID or GROUP scale. Once we had produced logistically accurate case documentation, based on transcript data with coded cultural bias scores indexed by task, statement, and time interval, we formatted it for use in the simulation.

The ORCiDS simulation used the respective task and statement list as inputs, indexed by time interval. For validation purposes, the task queue generated by ORCiDS was compared to the task queue documented by the coder in the archive, including when tasks were begun and when they were resolved. The quantity of tasks completed during a given time interval was also compared with the ORCiDS simulated output in order to assess the face validity of the model's operationalisation of cultural theory.

At the beginning of a simulation using ORCiDS, several initial conditions were set. GRID and GROUP were set to the corresponding GRID and GROUP of the organisation being modelled based on the initial assessment of its cultural bias. These scores were determined by the coder based on the descriptions of how the organisation in question had performed in a normal, everyday capacity based on the myths of nature and functional forms described above. The score was set at a midpoint, default condition. The fatalist organisation, for example, had scores of 75 and 25 for the GRID and GROUP midpoints respectively. The CT was set by examining the group's pre-existing plans for the mission (in the case documentation) and determining the level of resources they believed they would have available to them and that were necessary for the expected task load. In the case of a disaster, CT was set lower than for usual day-to-day organisational operations. A fatalist organisation that typically resolves four tasks per day, for example, might have its CT set to 1 or 2 for a disaster simulation.

Finally, the $\mathrm{Sp}$ for the hierarchist functional form was set. The value for $\mathrm{Sp}$ was always set to be greater than $\mathrm{CT}$, because a hierarchist organisation will not reach $\mathrm{Sp}$ unless it has first crossed CT. This captures the hybrid character of the hierarchists, 
explained above, as 'holding the line' until a disaster event takes the organisation's task resolution beyond ordinary limits, and the organisation responds with subsequent swift, immediate action that takes place as exponential task resolution.

An inter-rater reliability analysis using Cohen's Kappa statistic was performed to determine consistency between the two coders in their choice of coding category (Cohen, 1960). The reliability of the coders was found to be Kappa $=0.78(\mathrm{p}<0.01)$, indicating substantial agreement (Landis and Koch, 1977). In those cases where the two coders agreed on the category coding, the degree of inter-coder reliability for the GRID-GROUP coding was also calculated. The value of the intra-class correlation coefficient (rho $=0.87$ $\mathrm{p}<0.01$ ) indicates a high degree of coder agreement for this coding. In those few cases where coders disagreed in their choice of category, discussions took place amongst coders and researchers to determine the source of disagreement. In all cases, we found that disagreements stemmed from either an absence of information (e.g., a coder had recently been hired and was not as adept in reviewing documents and category coding) or a different reading of the context in which organisational representatives made statements or took actions. All disagreements were resolved through discussions by clarifying coding instructions and pooling documents to gain a fuller picture of the context in which statements were made or actions were taken by organisational representatives.

\section{Results}

Following the methods outlined above, cases were created for fatalist, individualist, egalitarian, and hierarchist organisations. Subsequently, these cases were entered into ORCiDS to establish face validity of the model. For the fatalist case, FEMA's establishment of a JFO was coded and simulated. The individualist case included President Bush and the White House declaration of Hurricane Katrina as a federal disaster. The egalitarian case focused on a group of approximately 30 out-of-state university students performing volunteer work in New Orleans during their 2007 Spring Break, while the hierarchist case modelled the Coast Guard performing rescues and evacuations in the aftermath of Hurricane Katrina.

For each simulation, tasks were identified on a daily basis (i.e., the time interval entered into the simulation was one day at a time), and the overall time period of task resolution for each organisation's mission was simulated for an overall period of approximately two weeks.

\subsection{FEMA establishing the JFO}

The FEMA case study took place over a time period of 18 days, beginning with the day of Katrina's landfall (August 25, 2005). It encompassed the efforts of FEMA to integrate its Incident Command Structure (ICS) with local Baton Rouge Emergency Operations Centers (EOCs). Although the JFO was never fully established according to FEMA's original stipulations, once the state and federal agencies had established respective bases of operations in Baton Rouge to fulfill the functions of a JFO, the mission of establishing a JFO no longer involved additional task resolution. The CT was set at 2, meaning that two incoming tasks per day were automatically resolved based on FEMA's projections of available resources (the remaining task resolution being taken up by the fatalist 
functional form). The initial cultural bias was set at a GRID of 75 and a GROUP of 25, in accordance with a fatalist organisation's median GRID and GROUP levels. The actual pattern of task resolution as coded in this case is depicted in Figure 6.

Figure 6 FEMA actual task resolution establishing the JFO

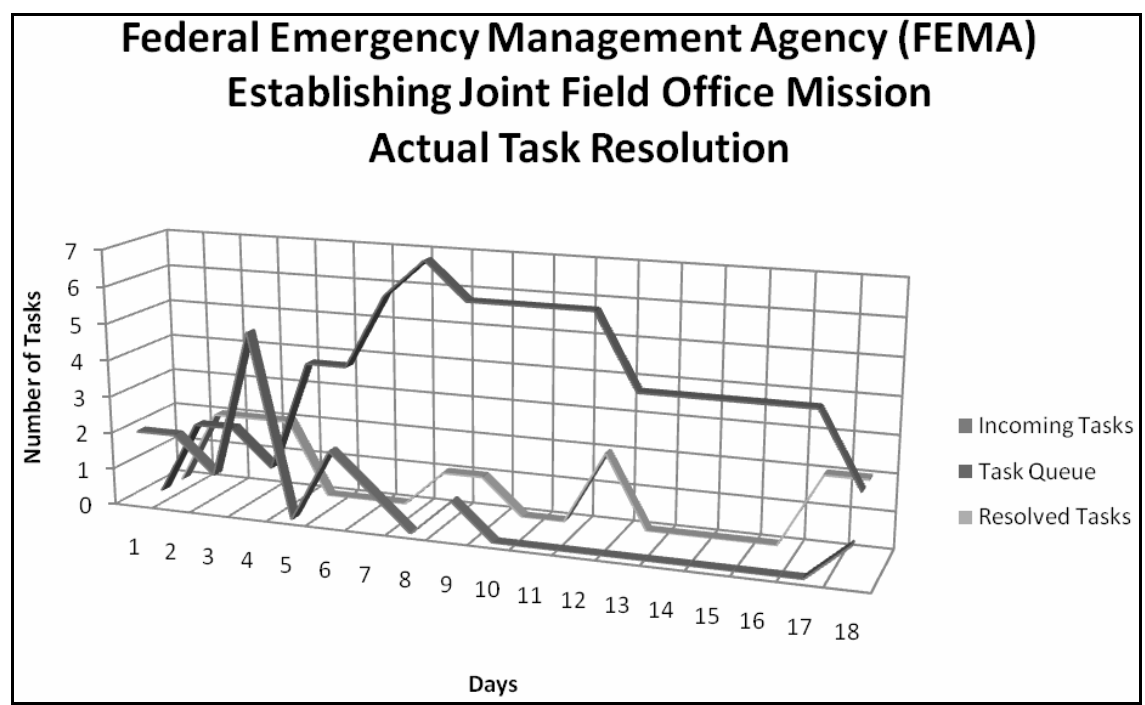

Using ORCiDS and the coded statement list, the simulation of FEMA's cultural bias showed a stable GROUP score at around 45, while the GRID score dipped from 75 to 45 by Day 4, and then became stable at a score of roughly 55 as seen in Figure 7.

Figure 7 FEMA's cultural bias score change

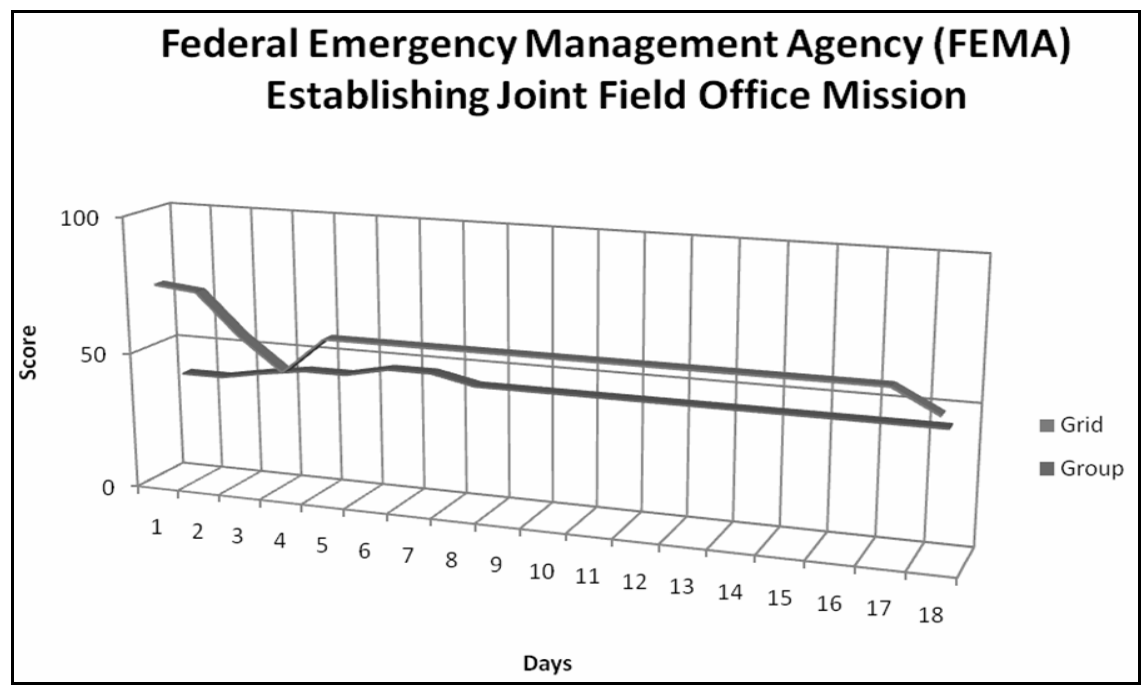


Our simulation of FEMA's organisational culture shows that on Day 4, the FEMA group assigned to establish the JFO adopted an individualist cultural bias. This corresponds to a large increase in incoming tasks on Day 4 , as seen in Figure 8.

Figure 8 FEMA task resolution simulated by ORCiDS

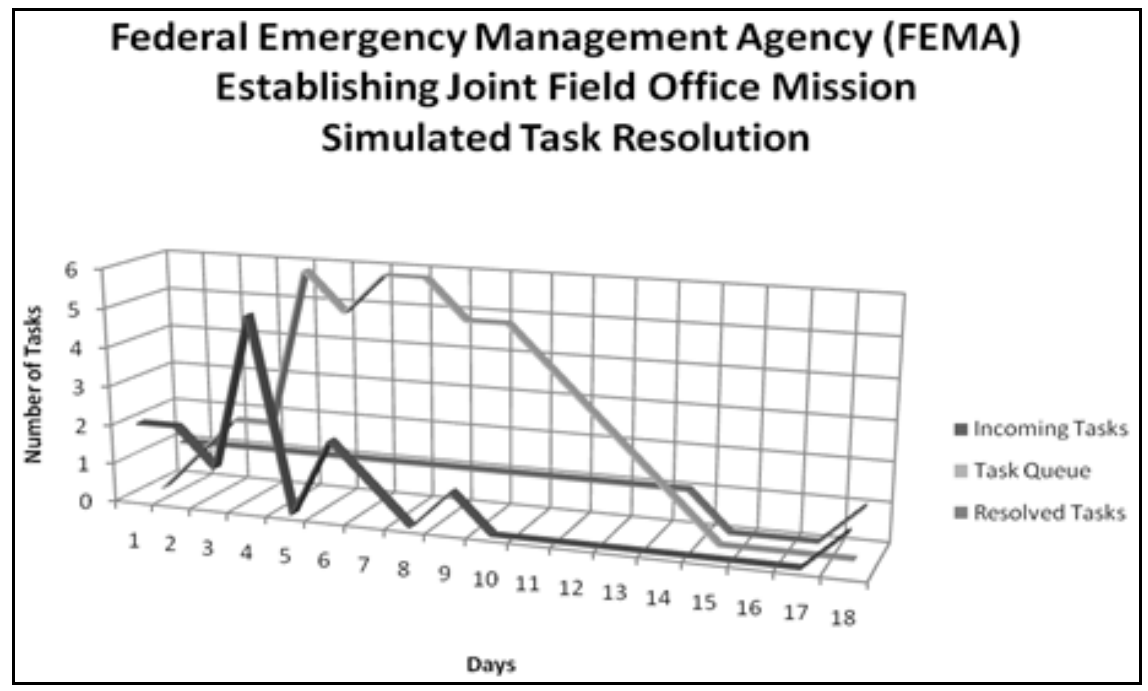

Because FEMA briefly switched its cultural bias to individualist during the relatively large increase in incoming tasks on Day 4, the ORCiDS simulation showed a sharp increase in backlog on Day 4. In actual task resolution, however, this queue continues to increase and remain, whereas in the ORCiDS simulation it does not. The ORCiDS' simulated pattern of a peak in backlog on Days 6 through 9 corresponds to that of the actual task resolution in terms of behaviour, though not in quantity (a peak of five backlogged tasks for the simulated case, as opposed to seven backlogged tasks in the actual case documentation). The simulated task resolution for Day 4 sees a peak that corresponds with the actual pattern of task resolution. For the rest of the mission time period, however, the simulation shows a steady pattern of resolution ending on Day 12, whereas on Day 12 and Day 18, there were spikes in actual task resolution that ORCiDS failed to model. Therefore, in this case, ORCiDS accurately simulated task resolution trends, but was imprecise in reflecting when specific spikes in task resolution actually took place.

\subsection{The White House declaring Hurricane Katrina a national disaster}

The White House case took place over 11 days (August 27 through September 6, 2005), and consisted of the Bush Administration's official recognition of Katrina as a national disaster and the mobilisation of appropriate resources to be delivered to responders in New Orleans. In addition to direct response actions, official White House statements referring to what needed to be done to respond to Katrina were considered tasks, as were White House meetings with key officials (such as New Orleans Mayor Ray Nagin and Louisiana Governor Kathleen Blanco), and the appointment of officials (Michael Brown as the Principal Federal Official, or PFO, for disaster response). The initial cultural bias 
of the White House was qualitatively assessed to be individualist, with GRID and GROUP both set at 25. Given the large number of resources at the disposal of the White House, CT was set at 5, meaning they could delegate resolution of five tasks per day before overextending routine organisational response.

Figure 9 Bush Administration actual task resolution

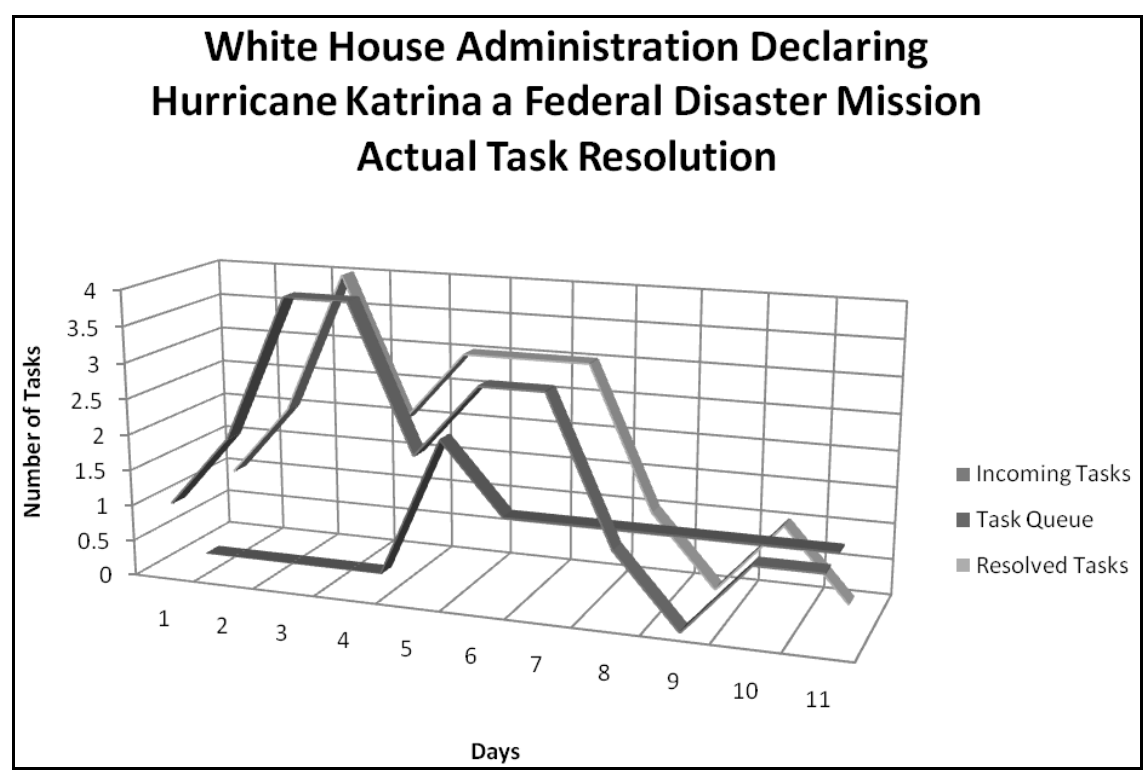

Figure 10 Bush Administration cultural bias score change

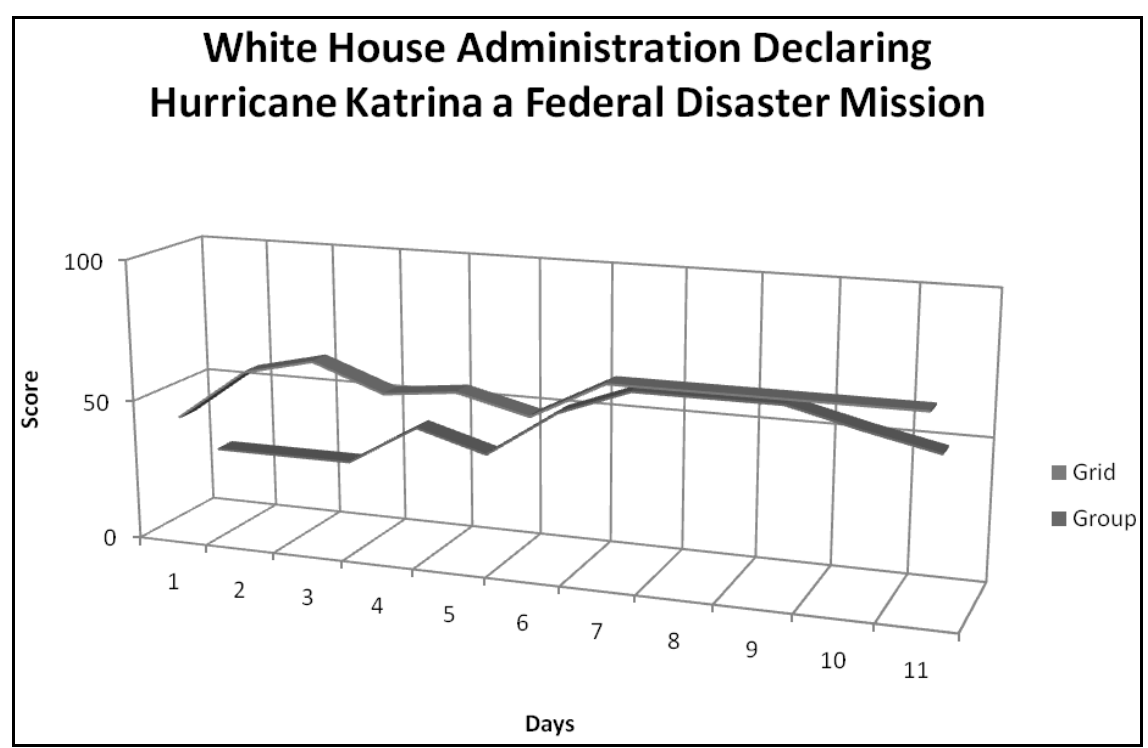


The actual number of incoming tasks peaked on August 29, four days after Katrina's landfall in Louisiana, then gradually tapered off. Tasks were resolved largely as they came in, bearing in mind once again that we regard delegation as task resolution, which does not speak to the effectiveness of the resolution itself (see Figure 9).

The simulation showed that White House representatives did not maintain a steady individualist bias throughout the 11 days. For the majority of the first week, the simulation showed the White House cultural bias as fatalistic. Then for the remaining days, it became predominantly hierarchist, as seen in Figure 9.

This borderline fatalist/hierarchist cultural bias of the White House suggests changes in GROUP levels within the organisation, but no significant changes in GRID levels. This could suggest uncertainty in the leadership and management within White House networks, and/or competing management styles and preferences. The simulated White House had ample resources, represented in the CT value (the number of incoming tasks was never higher than $\mathrm{CT}=5$ ), and tasks continued to be resolved on a daily basis (see Figure 11).

Figure 11 White House task resolution simulated by ORCiDS

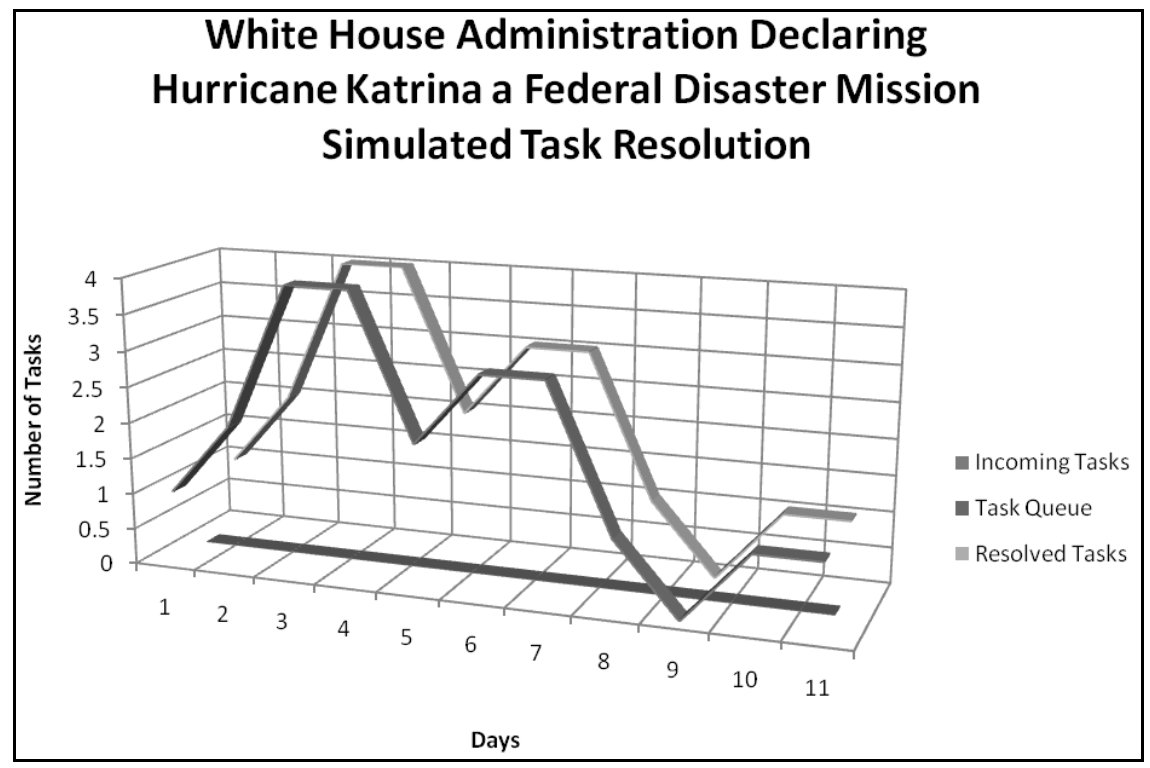

While actual and simulated patterns of White House task resolution were identical, the ORCiDS simulation predicted no backlog, although the actual pattern of task resolution showed a backlog of two tasks on Day 5, with one resolved the following day and the other remaining for the rest of the time period. It is interesting to note that this actual backlog reached its highest level during the end of a period when representatives adopted a fatalist cultural bias (Days 2 through 6) and that further backlog did not accrue after Day 7, when the simulation showed the dominant cultural bias to be hierarchist. This is consistent with the fatalist functional form, which predicts that fatalist organisations are prone to backlog when GRID and GROUP scores, as seen here, are marginally within the domain of the form. This is because such scores result in a low $\beta$ value for the form, $\beta$ here being the primary parameter that can decrease task resolution significantly because 
of its slope (see Figure 11). In this case, even with the backlog patterns of resolution differing, the ORCiDS simulation of cultural bias fluctuation accurately captured the actual overall task resolution pattern.

\subsection{United States Coast Guard Mission of Evacuation}

The US Coast Guard case ran over a time period of 15 days, from August 28 until September 12, 2005. The primary focus of the mission was the evacuation of Katrina victims who were stranded in New Orleans hospitals, homes, the Superdome, on the Causeway, and at other area sites. The organisation was qualitatively assessed to hold a pre-storm hierarchist cultural bias, with both high median GRID and GROUP scores of 75. Following Katrina's landfall, the anticipated level of resources needed to complete the mission was assumed to be quite high, while available resources within the city on a per capita basis were relatively low. To reflect this low resource availability relative to the potential resources needed to effectively complete the evacuation mission, CT was set at 2, as it was for the egalitarian student group ( 2 tasks per day resolved before entering post-CT task resolution patterns). The $\mathrm{Sp}$ was set at 5 (where tasks are resolved with the exponential character of egalitarians), the point at which Coast Guard personnel recognised the potential for extensive loss of life and property damage and responded accordingly. The actual pattern of incoming tasks and their resolution shows a significant influx of tasks on Day 2 and Day 7, with an increasing backlog through the course of the time period as one or two daily tasks accrue into backlog between the major influxes of tasks (see Figure 12).

Figure 12 USCG actual task resolution

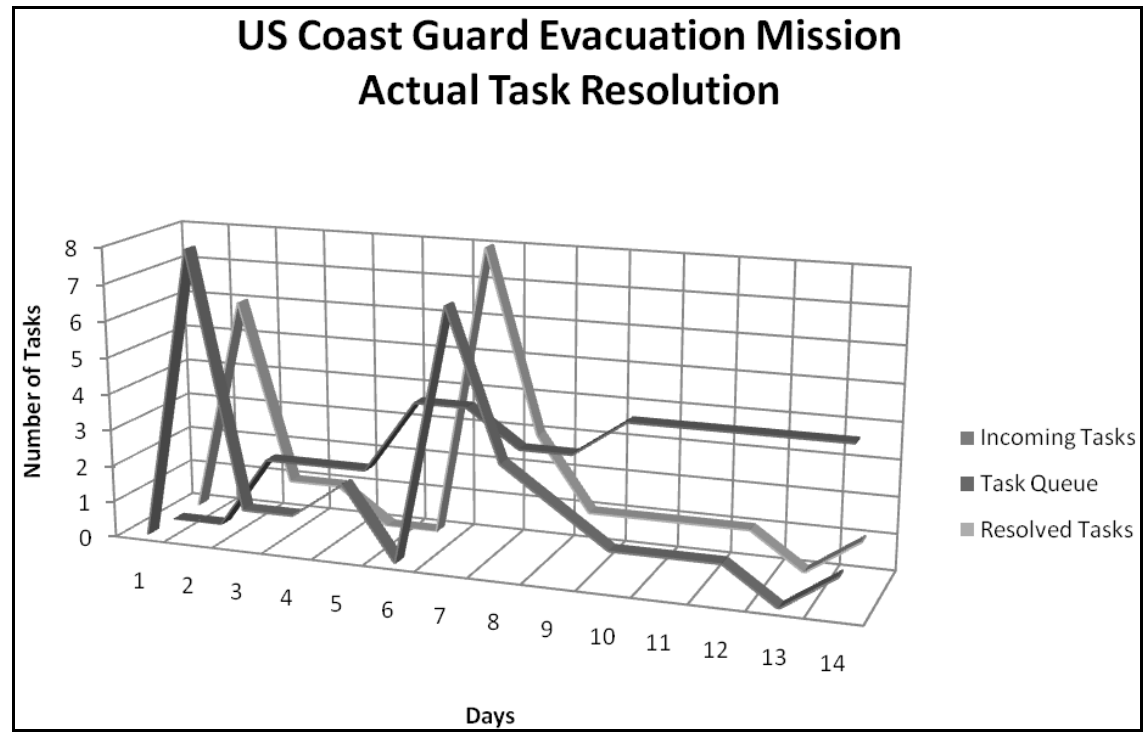

Consistent with initial qualitative assessments, the ORCiDS simulation showed that the US Coast Guard maintained a hierarchist cultural bias through the simulation period, with only minor variations (see Figure 13). 
The ORCiDS simulated task resolution was very similar to the actual pattern of task resolution, with some small variations. Most notably, the peaks of incoming tasks on Day 2 and Day 7 are resolved entirely in the simulation, whereas one task entered backlog in the actual scenario on Day 2, and an extra task was resolved on Day 7. Also, while backlog steadily accrues in the actual scenario, it peaks on Day 10 of the simulation (the same high point as the actual scenario), and then tapers off by the end of the simulation period as opposed to four tasks remaining unresolved in the actual scenario (see Figure 14).

Figure 13 USCG cultural bias score change

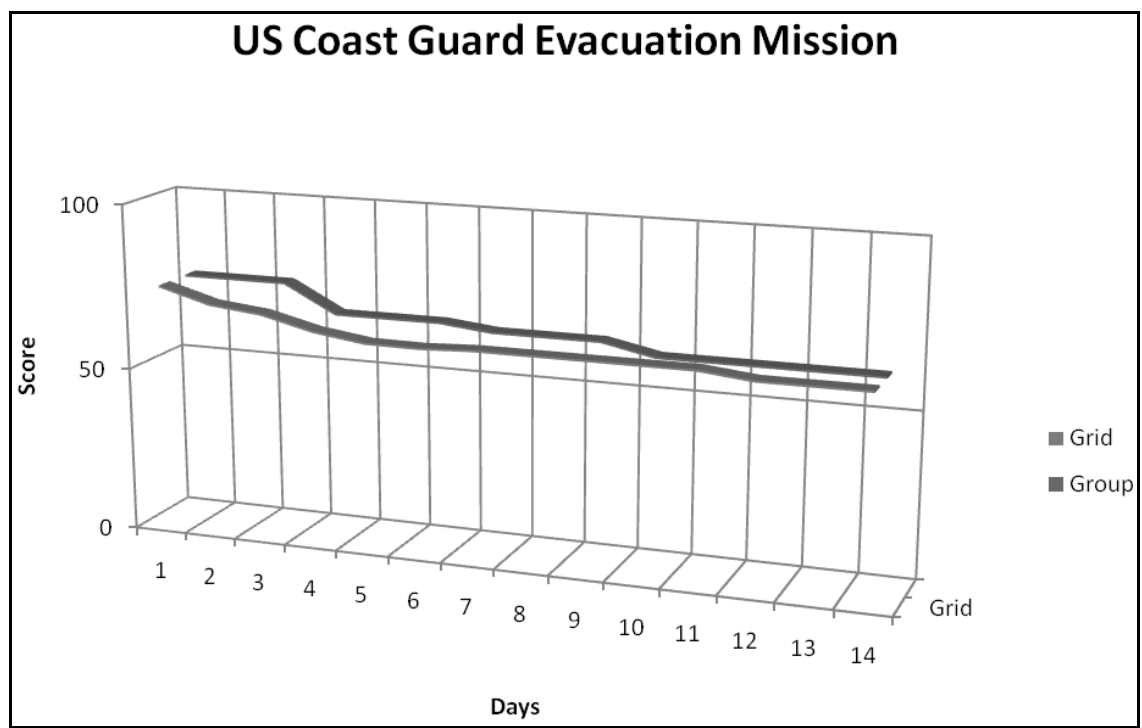

Figure 14 USCG task resolution simulated by ORCiDS

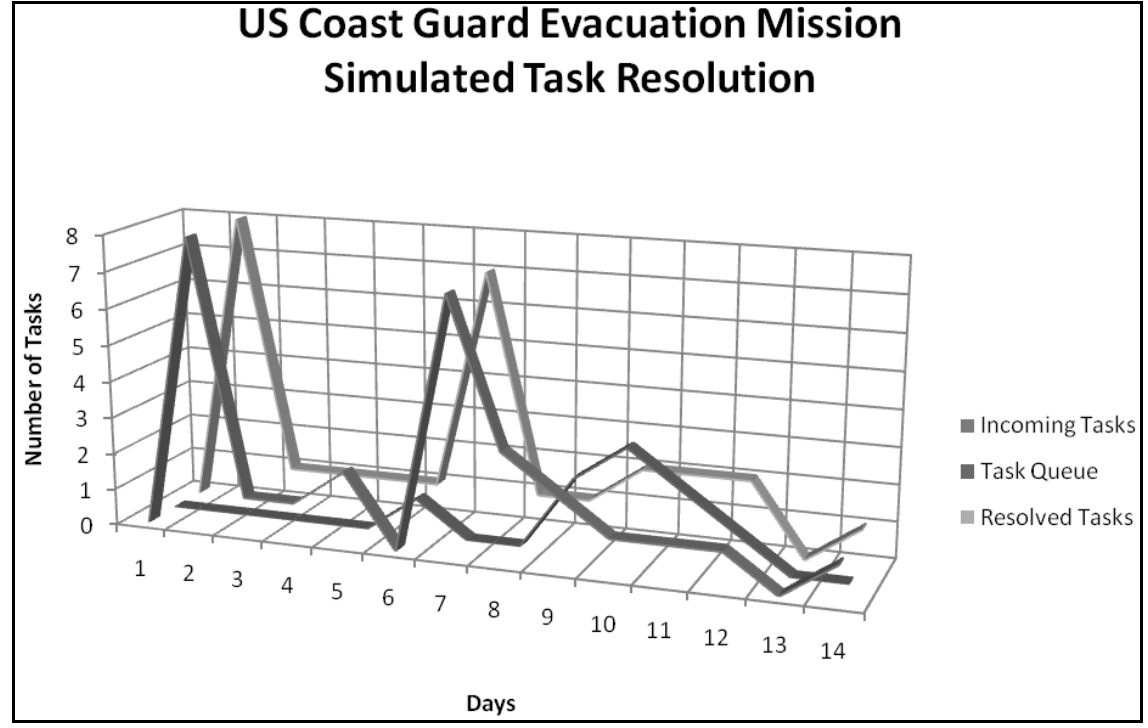




\subsection{University students performing volunteer work}

This case describes the efforts and experiences of a group of approximately 30 out-of-state student volunteers from a Texas university during their Spring Break in 2007, a time period of 16 days from March 3 to March 16. During this time, they worked with local community members to help refurbish local homes, administer health surveys to non-English-speaking groups, and otherwise perform daily duties under the leadership of the Common Ground Collective. Students kept a journal of their experiences and impressions of the work, which was used as the basis for coded statements. Given the nature of volunteering as a high-solidarity activity with no established procedures, the initial cultural bias was held to be egalitarian, with median scores of 25 for GRID, and 75 for GROUP. As a volunteer organisation, the student group's anticipated resource use and resource availability was low, with a CT set at 2 (2 tasks per day resolved before entering post-CT task-resolution patterns). The actual pattern of task resolution showed that tasks incoming for any given day were resolved that day, but with a persistent backlog of one task each day, as seen in Figure 15.

Figure 15 University students' actual task resolution

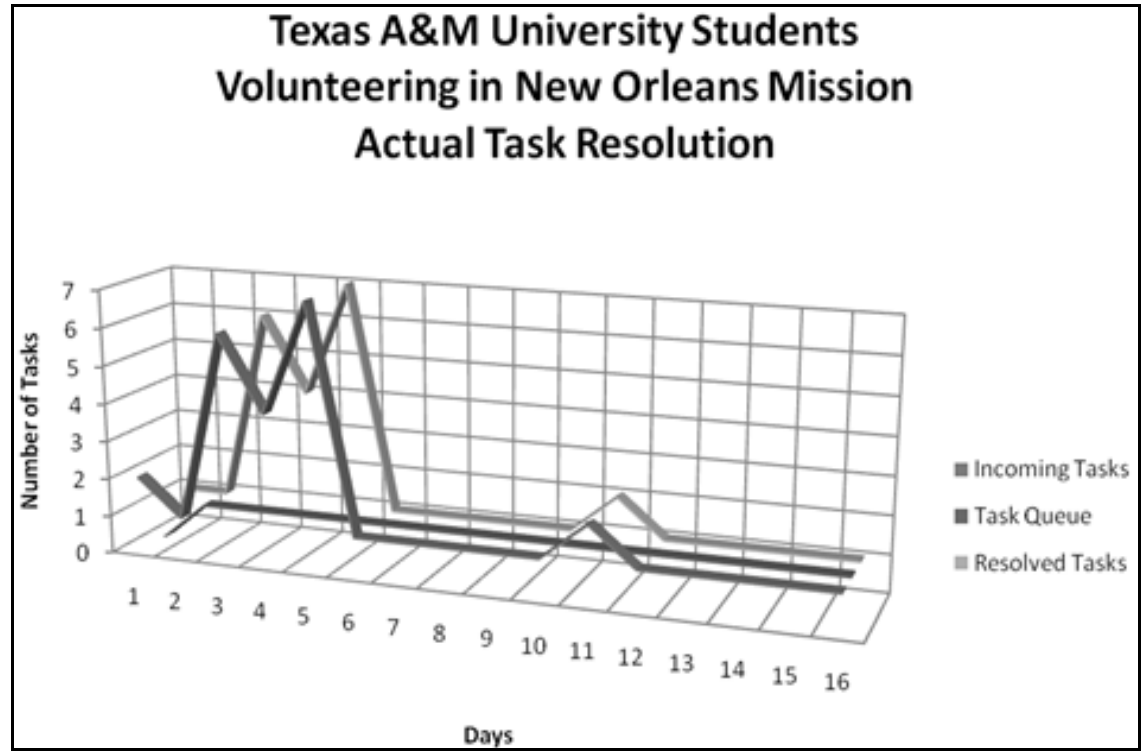

During this 16-day time period, the simulated cultural bias remained egalitarian, though the scores did tend towards 'low' scores for the egalitarian bias by the end of the period (a high GRID score of 45, and GROUP dropping as low as 51, both barely egalitarian). Figure 16 shows this pattern.

This is consistent between the initial cultural bias assumption and the results of the coded statements. The ORCiDS simulated task resolution matched the actual task resolution exactly, but predicted the absence of any backlog as opposed to the actual persistent backlog of one task every day during the actual pattern of task resolution and backlog (see Figure 17). 
Figure 16 University students' cultural bias score change

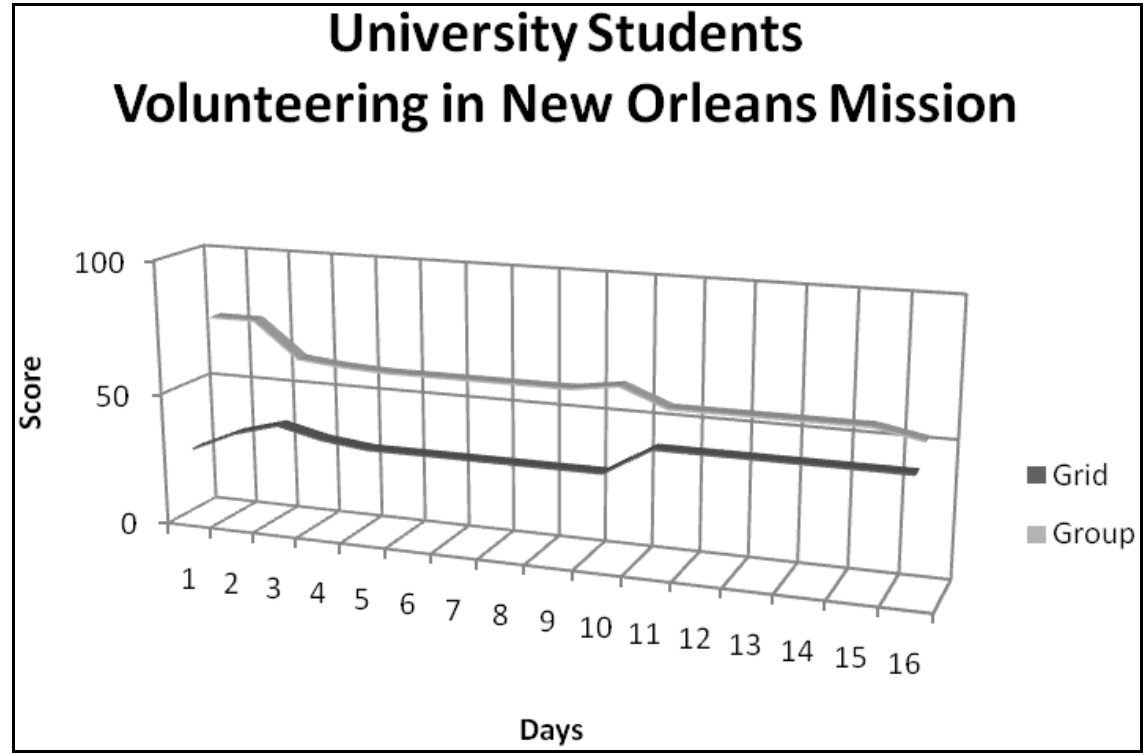

Figure 17 University students' task resolution simulated by ORCiDS

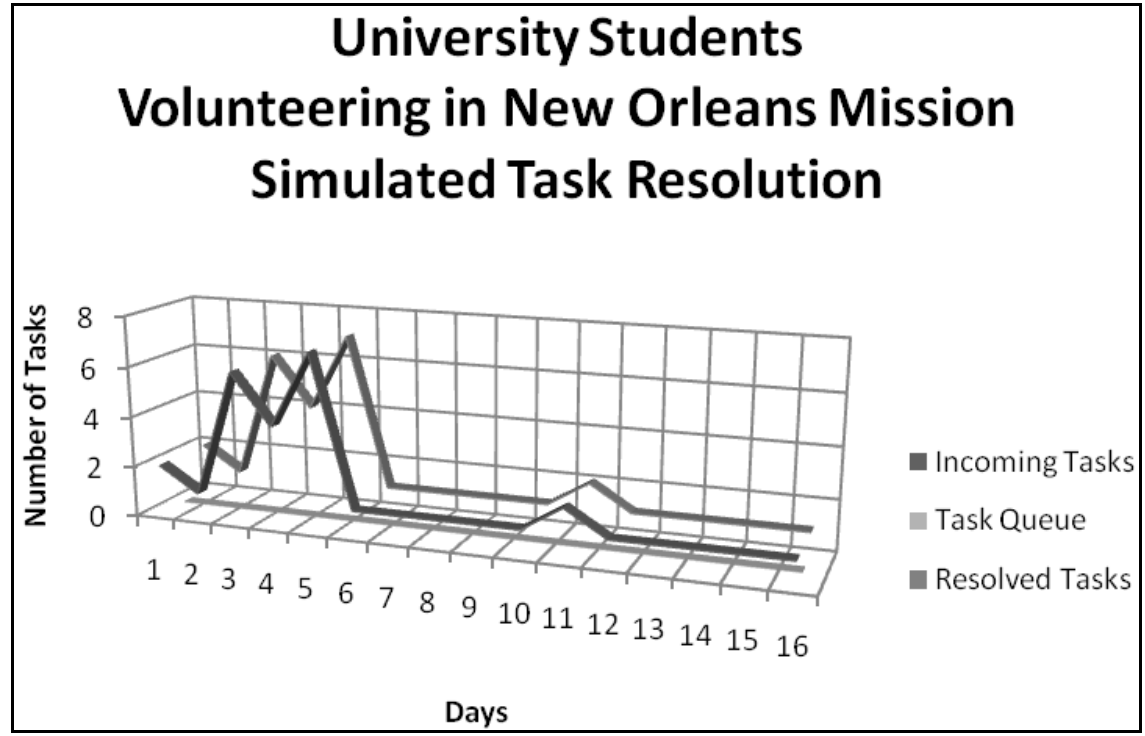

It is also worth noting that increasing $\mathrm{CT}$ to large values $(6+)$ does not affect the simulated pattern of task resolution, as both the pre- and post-CT periods of the egalitarian functional form resolve all incoming daily tasks in this simulation because the cultural bias began and remained egalitarian. If there had been a significant backlog due to the volunteer group having an individualist bias, as a counter example, the egalitarian 
functional form would have helped resolve the backlog. This suggests that while individualist task resolution capability is increased with (and dependent upon) increasing resource availability (translated as higher CT values), the effectiveness of egalitarian organisations is not contingent upon available resources. Instead, egalitarian organisations depend upon high (GROUP) solidarity and improvisation capabilities (i.e., low GRID and high GROUP), as discussed by Mendonça and Wallace (2007).

\section{Discussion and implications}

This study designed and implemented a computer simulation to detect a change in an organisation's culture as its representatives proceed in resolving tasks that result from an extreme event such as Hurricane Katrina striking New Orleans. To do this, we postulated functional forms based on Douglas' (1999) cultural bias theory and the developments of her theory made by Thompson et al. (1990). Using these functional forms, we developed a computer simulation, Organizational Response Culture in Disaster Simulation (ORCiDS) to model what happens to organisational cultures as personnel resolve incoming disaster tasks. Finally, we developed a method for coding source-verified press articles, transcripts, and other qualitative data into narrative scenarios with substantive inter-coder reliability. We then simulated four narrative scenarios with ORCiDS to determine whether and at what point in its response each organisation changed its cultural bias, if at all. Our simulation results suggest that the organisational cultures of FEMA, the US Coast Guard, a volunteer student group, and the White House fluctuated during their respective responses to crises, but did not undergo any sustained changes. Narratives compiled from documents for each organization show that subgroups representing an organisation during an extreme event do not always maintain the culture of their parent organisation while resolving crisis tasks. In fact, effective task resolution and disaster remediation may require that a group adjust its cultural bias to suit the novelty of an extreme event. This provides important insights and an empirical contribution called for in understanding what Romanelli (1991) describes as the genesis of new cultural forms. It also confirms that groups responding to non-routine tasks will draw upon resources in non-routine ways with non-routine organisational forms in order to provide effective remediation, even when such innovations are counter to the cultural and organisational forms of their parent organisations (Majchrzak et al., 2007).

The simulation results also suggest that organisations would benefit greatly from being able to assess their cultural bias accurately and understand how it relates to task-resolution patterns. This would provide valuable insights into routine task-resolution patterns, and depending on the predominant cultural bias, into what organisational changes would provide the most benefit in increasing effectiveness at task resolution during extreme events. Possible strategies such as increasing available resources, for example, would be beneficial to individualist organisations, whereas egalitarian organisations would benefit more directly from fewer regulations and from increases in group solidarity during disaster response. However, such proscriptions for organisational change could only be made after specific information is gathered about a specific organisation after an extreme event, to help prepare and improve response for future crises. Such changes would afford managers the possibility of directly influencing their 
organisation's cultural bias to enhance effectiveness, and in the case of new organisations and organisational forms, to overcome the liability of newness (Stinchcombe, 1965).

\subsection{Implications of a fatalist culture responding to extreme events}

With few resources at the outset of a disaster, the ORCiDS results suggest that the Fatalist organisation, generally speaking, is not responsive to crisis in the short term or when large volumes of incoming tasks occur. This is in spite of the fact that fatalist organisations usually have comprehensive procedures governing and suggesting action in such circumstances. In the post-CT period, fatalist organisations seem prone to allowing backlog to occur and grow, most likely due to ambiguity present in the novelty of the disaster context. In such cases, even though the highly rigid nature of the fatalist organisation while executing procedures should enable swift and specific action, the disaster context seems to overload or create conflicting patterns of procedure. Until the appropriate course of action is determined, task backlog will accumulate. As seen in both the actual and simulated patterns of results, determining the appropriate course of action appears to require time - and time alone - as the means of recovering task resolution effectiveness.

Put in a positive light, this conclusion suggests that even when faced with insurmountable task backlog and confusion over which procedures to prioritise and execute, the fatalist organisation will be persistent in its daily efforts to remediate backlog and will continue until the situation is under control. Whereas other functional forms may quickly dispatch a backlog with an exponential effort (tempered of course by the effect of organisational culture, coded statements, and the determination of the $k$ variable), such efforts may be at the expense of collateral damage that fatalist or individualist managers would find unacceptable. Fatalist organisations appear to continue and persist with the worldview they begin with (in our case, the ultimate goal of establishing a JFO), even when the compelling need for the goal has already passed. FEMA did not seem to concede or re-prioritise to a significant degree. This suggests its execution remained consistent, but only at the expense of timeliness and responsiveness.

\subsection{Implications of an individualist culture responding to extreme events}

With a LOW GRID and LOW GROUP configuration and ample resources, an individualist organisation's employees may be prone to fluctuating GRID and GROUP levels and borderline changes in cultural bias when tasked with responding to extreme events in the name of their parent organisation. Although this may seem counter to an individualist's Nature-Benign myth of nature, which dictates that organisational representatives lock on to a certain set of responses and perform them repeatedly to 'hold the line', escalating crisis contexts may push the 'line' of organisational representatives to adopt marginally different strategies (in the short term) than those their organisation typically uses for task resolution.

In the case of the White House declaring Hurricane Katrina a national disaster, the routine 'hold the line' approach to allocating resources and resolving tasks (such as delegating authority and attending meetings with state and local officials) may have worked for President Bush and his immediate aides. When failure of resource allocation 
and of social and political networks occurred, however, White House representatives showed an overall trend toward increasingly applying rules and regulations (thereby increasing GRID) to resolve incoming tasks associated with the mission we studied (i.e., declaring Katrina a national disaster). This tendency toward using more rules and regulations would account for why the ORCiDS simulation suggested that some White House representatives adopted a borderline fatalist (HIGH GRID, LOW GROUP) cultural bias to resolve tasks during Days 2 through 4 of the mission. Their GROUP levels during this time remained low, according to the dominant individualist White House cultural bias, but an increase in GRID would shift a segment of the organisation working to resolve this mission toward a fatalist culture.

However, beginning on Day 7, White House representatives began banding together, indicated by increasing GROUP levels. From Day 7 until Day 9, the combined effect of increasing GRID and GROUP levels resulted in these White House representatives adopting a hierarchist (HIGH GRID, HIGH GROUP) cultural bias. On Day 9, GROUP levels began to fall again, and the simulation shows that Days 10 and 11 brought these White House representatives back to a borderline fatalist cultural bias.

\subsection{Implications of an egalitarian culture responding to extreme events}

Student volunteers set out from their university campus during their Spring break following Katrina, fully expecting to find disaster, which indeed defined the purpose of their journey. This was consistent with the egalitarian myth of nature, which dictates that resources are limited and that disaster is the expected norm as tasks arrive rapidly and must be resolved rapidly to avoid organisational collapse. This student volunteer group at Common Ground Collective tended toward mid-scores of GRID and GROUP as an overall trend, i.e., their HIGH GROUP scores showed a lowering trend and their GRID scores showed an overall increasing trend over the course of the time period examined, although the simulation shows they remained an egalitarian organisation.

Egalitarian organisations generally depend upon HIGH GROUP solidarity and improvisation (LOW GRID) to resolve tasks. While clearly remaining an egalitarian organisation, the trend seen in the student volunteer group toward adopting more rules and decreasing their dependency on each other may have implications for tendencies of this organisational culture during extreme events. While resolving disaster tasks, egalitarian organisational representatives may get cut off from their typical bonds and seek order by applying rules to task resolution strategies when they otherwise might look to each other and their bonds of solidarity. One important aspect of solidarity is communication, which tends to get interrupted or cut off entirely in some crisis situations.

\subsection{Implications of a hierarchist culture responding to extreme events}

The immediately striking thing about hierarchist organisations, such as the United States Coast Guard in this paper, is their capacity to resolve a large number of tasks on the day that they are incoming. There are several qualifying reasons for this ability. The first is that despite being a HIGH GRID organisation with a plethora of procedures, just as fatalist organisations implement, the hierarchist organisation emphasises the ability to reflect upon its own procedures, and where necessary, to change them. This does not 
reflect a tendency to favour ad hoc solutions, but rather the benefits of the 'hold the line' characteristic leading up to the structural change point and also a willingness to reprioritise and recharacterise the requirements of the mission as task backlog begins to occur. As a practical example in our own research, it was standard practice for searchand-rescue teams to carry highly effective power tools with them to extricate victims trapped in attics. During Katrina, however, the electrical power or gasoline necessary to operate such devices was not readily available, and the number of trapped victims began to rise as a task backlog. During the reflection and self-assessment period, it was suggested that the relatively mundane fire axe become the standard piece of equipment for such tasks, with a large degree of success. Such procedural innovations are the hallmark of the hierarchist organisation.

Also worth considering, however, are the consequences such innovations have on reassessing the role of collateral damage in procuring solutions to rising task backlog. fatalists, for example, would find solutions that are inherently destructive to private property unacceptable if their procedures were against it. Hierarchists, who place the priority of safety over property damage, however, can perform significant infrastructure damage to meet their goals past the structural change $(\mathrm{Sp})$ point, a consequence of their high GROUP alignment. As a counterpoint to this aspect of hierarchist task resolution, however, the acceptable level of collateral damage is an aspect of post-Sp behaviour; task resolution that is pre-CT and pre-Sp will be of the same 'hold the line' character as the individualists, relying on the natural resilience of the local ecology before resorting to extreme methods. In this respect, the hierarchist cultural bias seems to offer the best of both worlds, depending upon the novelty of the tasks to the organisation, the resources available, and the extreme nature of the event.

\subsection{Collective implications of simulating organisational cultures' responses to crises}

For all four of the cultural biases, task resolution diminishes the most the further the scores are from the 'ideal' or 'pure' point. For example, a fatalist organisation with a score of $(100,1)$ is ideal, meaning that the $\beta$ value is 0.99 for the post-CT period. Contrast that with a score of $(51,50)$, and the $\beta$ value becomes 0.01 , capping the organisation's task resolution at CT. For an organisation with an already low CT, this score would indicate a high level of inability to resolve tasks. It follows that for each of the four biases, competing cultural elements in an organisation that lead to marginal cultural bias scores are the least effective at providing task resolution. Put another way, while all four elements are present within any organisation at any given time, organisational effectiveness is compromised when two or more cultural biases are equally present and competing with one another to dominate the organisation.

\section{Conclusions}

This research contributes to the understanding of the circumstances under which an organisation's culture will change when confronted with disaster. The ORCiDS computer simulation enables researchers and organisational administrators to reflect upon a previous disaster responses and make appropriate plans and cultural changes to mitigate 
against repeating errors during future crises and remain resilient after enduring an extreme event. Beyond the specific case of disaster response we consider, this research demonstrates the value of modelling and simulating basic notions about organisational culture in order to understand organisational behaviours. The research also demonstrates the utility of Douglas' (1999) GRID-GROUP delineation of organisational culture in predicting differential organisational responses to crises.

The simulation is pioneering in presenting, to our knowledge, the first empirical modelling of Douglas' framework. As with any new research direction, there are limitations. The research used data from one extreme event, Hurricane Katrina, to support the formulation of the model and its use for the computer simulation. The methods we used to gather and code the data can be replicated. However, the data collection and coding of organisational responses were time consuming. Use of content-analysis software (such as ATLAS.ti) may help reduce this time and speed up the coding process. Given the fact that we considered one case of extreme events (albeit with four types of organisations), the generality of the implications of the modelling must await the application of ORCiDS to other extreme events and crisis contexts.

We show how the various forms of organisational culture that Douglas identifies can be measured and modelled in meaningful ways. This is in itself novel, but the value of doing this comes from the simulation of the effects of culture on how organisations resolve disparate and novel tasks in disaster responses.

The simulation has a number of implications beyond helping to diagnose the organisational failures in the Katrina response. Consider, for example, the interplay of different organisations as they collaborate in times of crisis. FEMA's dominantly fatalist culture clashed with the dominant individualist culture of Universe Truck Lines when the former contracted the latter to deliver ice to Hurricane Katrina victims, while the dominantly egalitarian culture of the Southern Africa Development Community clashed with the dominantly hierarchist culture of the World Food Programme when the former refused the latter's offer of genetically-modified maize to alleviate mass hunger after two years of extreme weather events (Dowty and Wallace, 2010).

Establishing a 'bank' of scenarios based on simulations of how different organisations respond to extreme events could lead to prescriptions for organisational collaboration in crisis response. Such comparative scenario-building and cultural assessment work could lead to greater understanding of the issues that are likely to arise when collaborating organisations have different lenses for interpreting and resolving the tasks they are being asked to undertake. These and other practical applications of organisational culture must be brought to bear on what remain complex theoretical constructs, so that avoidance of culture clashes in response to extreme events does not remain a hit-or-miss outcome.

\section{Acknowledgements}

Financial support for this research is provided by the National Science Foundation (NSF), Small Grants for Exploratory Research (SGER) grant number SES-0554938, and Human and Social Dynamics grant number SES-0623907 made to Rensselaer Polytechnic Institute under Principal Investigator William Wallace. NSF is not responsible for data, analyses or claims made by the authors. 


\section{References}

Altman, Y. and Baruch, Y. (1998) 'Cultural theory and organizations: analytical method and cases', Organ. Stud., Vol. 19, No. 5, pp.769-785.

Belardo, S., Pazer, H.L., Danko, W.D. and Wallace, W.A. (1983) 'Simulation of a crisis management information network: a serendipitous evaluation', Decision Sci., Vol. 14, No. 4, pp.588-606.

Carroll, G. and Harrison, J.R. (1998) 'Organizational demography and culture: insights from a formal model and simulation', Admin. Sci. Quar., Vol. 43, No. 3, pp.637-667.

Chatman, J.A. and Jehn, K.A. (1994) 'Assessing the relationship between industry characteristics and organizational culture: how different can you be?', Acad. of Management J., Vol. 37, No. 3, pp.522-553.

Chatman, J.A., Polzer, J.T., Barsade, S.G. and Neale, M.A. (1998) 'Being different yet feeling similar: the influence of demographic composition and organizational culture on work processes and outcomes', Admin. Sci. Quar., Vol. 43, No. 4, pp.749-780.

Cohen, J. (1960) 'A coefficient of agreement for nominal scales', Ed. and Psych. Measurement, Vol. 20, No. 1, pp.37-46.

Comfort, L.K., Ko, K. and Zagorecki, A. (2004) 'Coordination in rapidly evolving disaster response systems: the role of information', The Amer. Behavioral Scientist, Vol. 48, No. 3, pp.295-313.

Coyle, D.J. (1997) 'A cultural theory of organizations', in Ellis, R. and Thompson, M. (Eds.): Culture Matters, pp.59-78, Westview Press, Boulder.

Coyle, D.J. and Ellis, R.J. (Eds.) (1994) Politics, Policy, and Culture, Westview Press, Boulder.

Douglas, M. (1994) Risk and Blame: Essays in Cultural Theory, Routledge, London.

Douglas, M. (1999) 'Four cultures: the evolution of a parsimonious model', GeoJournal, Vol. 47, No. 3, pp.411-415.

Douglas, M. (Ed.) (1982) Essays in the Sociology of Perception, Routledge and Kegan Paul, London.

Douglas, M. and Wildavsky, A. (1983) 'Risk and culture: an essay on the selection of technological and environmental dangers', University of California Press, Berkeley.

Dowty, R., May, P.J., Beech, C.E. and Wallace, W.A. (2011) 'Organizational culture and the Katrina Response in Louisiana', in Dowty, R. and Allen, B. (Eds.): Chapter 2 in Dynamics of Disaster: Lessons on Risk, Response, and Recovery, Earthscan, London.

Dowty, R.A. and Wallace, W.A. (2010) 'Implications of organizational culture for supply chain disruption and restoration', International Journal of Production Economics, Vol. 126, No. 1, pp.57-65.

Ellis, R.J. and Thompson, F. (1997) 'Culture and environment in the Pacific Northwest', Amer. Pol. Sci. Rev., Vol. 91, No. 4, pp.885-897.

Frosdick, S. (1995) 'Safety cultures' in British stadia and sporting venues: understanding cross-organizational collaboration for managing public safety in British sports grounds', Disaster Prevention and Management, Vol. 4, No. 4, pp.13-21.

Grendstad, G. and Selle, P. (1997) 'Cultural theory, postmaterialism, and environmental attitudes', Ellis, R.J. and Thompson, M. (Eds.): Culture Matters: Essays in Honor of Aaron Wildavsky, Westview Press, Boulder.

Harrison, J.R. and Carroll, G.R. (2002) 'The dynamics of cultural influence networks', J. of Computational and Math. Organ. Theory, Vol. 8, No. 1, pp.5-30.

Hood, C. (1998) The Art of the State: Culture, Rhetoric, and Public Management, Oxford University Press, Oxford.

Klein, R.L., Bigley, G.A. and Roberts, K.H. (1995) 'Organizational culture in high reliability organizations: an extension', Human Relations, Vol. 48, No. 7, pp.771-793. 
Landis, J.R. and Koch, G.G. (1977) 'The measurement of observer agreement for categorical data', Biometrics, Vol. 33, No. 1, pp.159-174.

Lin, Z. (2002) 'The dynamics of inter-organizational ties during crises: empirical evidence and computational analysis', Simulation Model, Practice and Theory, Vol. 10, Nos. 5-7, pp.387-415.

Lin, Z. and Carley, K.M. (2003) Designing Stress Resistant Organizations: Computational Theorizing and Crisis Applications, Kluwer Publishers, Boston.

Lin, Z., Zhao, X., Ismail, K.M. and Carley, K.M. (2006) 'Organizational design and restructuring in response to crises: lessons from computational modeling and real-world cases', Organ. Sci., Vol. 17, No. 5, pp.598-618.

Maesschalck, J. (2004) 'Research note: a method for applying cultural theory in the study of organizations', Innovation, Vol. 17, No. 4, pp.377-386.

Majchrzak, A., Jarvenpaa, S.L. and Hollingshead, A.B. (2007) 'Coordinating expertise among emergent groups responding to disasters', Organ. Sci., Vol. 18, No. 1, pp.147-161.

Marcoulides, G.A. and Heck, R.H. (1993) 'Organizational culture and performance: proposing and testing a model', Organ. Sci., Vol. 4, No. 2, pp.209-225.

Mendonça, D.J. and Wallace, W.A. (2007) 'A cognitive model of improvisation in emergency management', IEEE Transactions on Systems, Man, and Cybernetics, Part A, Vol. 34, No. 4, pp.547-556.

MKC-EPU (2004) 'Milton Keynes Council Emergency Planning Unit: integrated emergency management', available at http://www.mkweb.co.uk/emergencyplanning/documents/IEMv1_2.pdf (accessed on 11 September 2012).

Ouchi, W.G. and Wilkins, A.L. (1985) 'Organizational culture', Annual Rev. of Sociology, Vol. 11, pp.457-483.

Perrow, C. (1994) 'Accidents in high-risk systems', Tech. Stud., Vol. 1, No. 1, pp.1-19.

Poortinga, W., Steg, L. and Vlek, C. (2002) 'Environmental risk concern and preferences for energy-saving measures', Environ. and Behavior, Vol. 34, No. 4, pp.455-478.

Prietula, M.J., Carley, K.M. and Gasser, L. (Eds.) (1998) Simulating Organizations: Computational Models of Institutions and Groups, AAAI/MIT Press, Menlo Park, CA.

Rayner, S. (1992) 'Cultural theory and risk analysis', in Krimsky, S. and Golding, D. (Eds.): Soc. Theories of Risk, pp.83-115, Praeger, Westport, CT.

Rippl, S. (2002) 'Cultural theory and risk perception: a proposal for a better measurement', J. of Risk Res., Vol. 5, No. 2, pp.147-165.

Romanelli, E. (1991) 'The evolution of new organizational forms', Annual Rev. of Sociology, Vol. 17, pp.79-103.

Rudolph, J. and Repenning, N. (2002) 'Disaster dynamics: understanding the role of quantity in organizational collapse', Admin. Sci. Quar., Vol. 47, No. 1, pp.1-30.

Schulman, P.R. (1993) 'The analysis of high-reliability organizations: a comparative framework', in Roberts, K.H. (Ed.): New Challenges to Understanding Organizations, pp.33-54, Macmillan, New York.

Shrivastava, P., Mitroff, I., Miller, D. and Miglani, A. (1988) 'Understanding industrial crises', $J$. of Management Stud., Vol. 25, No. 4, pp.285-303.

Smircich, L. (1983) 'Concepts of culture and organizational analysis', Admin. Sci. Quar., Vol. 28, No. 3, pp.339-358.

Stinchcombe, A.L. (1965) 'Social structure and organizations', in March, J.G. (Ed.): Handbook of Organizations, pp.142-193, Rand McNally and Company, Chicago.

Thompson, M., Ellis, R. and Wildavsky, A. (1990) Cultural Theory, Westview Press, Boulder.

Tierney, K.J., Lindell, M.K. and Perry, R.W. (2001) Facing the Unexpected: Disaster Preparedness and Response in the United States, Joseph Henry Press, Washington, DC. 
Turner, B.A. (1978) Man-Made Disasters, Wykeham, London.

Vaughan, D. (1996) The Challenger Launch Decision: Risky Technology, Culture, and Deviance at NASA, University of Chicago Press, Chicago.

Weick, K.E. (1993) 'The collapse of sensemaking in organizations: the Mann-Gulch disaster', Admin. Sci. Quar., Vol. 38, No. 4, pp.628-652. 